\title{
Las tecnologías de la información y comunicación como apoyo pedagógico en el proceso de lecto- escritura de educación preescolar de las secciones de niños de 6 años de centros edu- cativos públicos y privados de la ciudad de Santa Ana
}

Antonia Larissa Hernández Monterrosa

Máster en Profesionalización de la Docencia Superior Investigadora-docente, Dirección de investigación Universidad Católica de El Salvador, El Salvador

Email: larissa.hernandez@catolica.edu.sv

Recepción: 30-09-2015 / Aceptación: 12-11-2015

\section{Resumen}

Uno de los objetivos en la educación parvularia es preparar a los niños por medio del apresto para que aprendan a leer y a escribir. Este proceso comprende una serie de métodos, técnicas y estrategias para encaminar al estudiante a que logre lo antes mencionado; sin embargo, en el sector público solamente se trabajan las nociones de las letras al igual que la lectura. Por el contrario, en el sector privado, los estudiantes de la sección de preparatoria pasan al siguiente nivel educativo leyendo y escribiendo. Actualmente, las docentes que educan a párvulos siempre hacen uso de métodos tradicionales para la lecto-escritura.

Aunque es importante mencionar que hace unos años se han incorporado las Tecnologías de Información y Comunicación (TIC)[1] como un apoyo para innovar el aprendizaje y hacerlo más dinámico, cabe señalar que en las instituciones privadas se cuenta con mayores facilidades de equipo tecnológico que en las instituciones públicas. No obstante, en estas últimas se hacen esfuerzos por parte de los docentes para incorporarlas y aprovecharlas en las clases. Además, con la investigación se alcanzaron los objetivos de identificar, describir y evaluar las estrategias metodológicas y recursos que implementan las docentes de educación preescolar utilizando las TIC en el proceso de lecto-escritura, asimismo, el de evaluar la integración curricular de estas en el proceso. Finalmente, se abordó desde un planteamiento Explicativo-descriptivo ya que tuvo como propósito explicar las condiciones del uso de las estas como apoyo en la enseñanza de la lecto-escritura.

Palabras clave: aprestamiento, TIC, lecto-escritura, software educativo, metodología

\begin{abstract}
One of the goals in early childhood education is to prepare children through exercises to learn to read and write. This process involves a number of methods, techniques and strategies to guide the student to achieve the above; however, in the public sector only notions of letters as well as the reading. By contrast, in the private sector, pre-school students advance to the next educational level reading and writing. Currently, the kindergarten teachers who educate always make use of traditional methods of reading and writing.

While it is important to mention that a few years ago the Information and Communication Technologies (ICT ) have joined as a support for innovation and learning and make it more dynamic, private institutions have major facilities in the technological equipment than public institutions. However, in latter ones efforts are made by teachers to incorporate and use them in class. Furthermore, research objectives identify, describe and evaluate methodological strategies and resources that implement preschool teachers using ICT in the process of literacy also to evaluate the curricular integration of these were achieved in process. Finally, it was approached from a descriptive approach Explanatory-descriptive as it had intended to explain the conditions of use of these to support the teaching of reading and writing.
\end{abstract}

Key Words: preparation, ICT, Reading-writing, learning software, methodology 


\section{Introducción}

La educación como sistema social dinámico tiene un accionar permanente, orientado a desarrollar y mejorar sus procedimientos. Al enfocarse en el área de preescolar, un proceso que puede mejorarse es la enseñanza de la lectura y la escritura, ya que es donde la docente de este nivel tiene que perfeccionar las habilidades y destrezas en los estudiantes, para que ellos logren alcanzar el objetivo de aprender a leer y escribir, apoyándose en varios métodos, técnicas y estrategias. El proceso de lecto-escritura se inicia formalmente entre las edades de 4 a 6 años, pero existe mayor énfasis y exigencia en esta última edad. La lecto-escritura - por lo general - se origina por medio de juegos, de tal manera que el niño no sienta que es una obligación leer y escribir - o en el peor de los casos - que desarrolle aversión por este proceso.

El proceso de lecto-escritura en Educación Preescolar es complejo. Desde siempre, este ha sido - y es -, una carta de presentación de la labor docente; convirtiéndose en la base primordial de la educación, ya que de ella depende el desarrollo de capacidades en los niños para expresar sus ideas con claridad, sencillez y coherencia. Para tener una definición más clara de lecto-escritura, Sánchez (2010) lo explica como «un proceso intelectual; mediante en el que se transforma un código de formas geométricas o signos orales» (p.1).

Hoy, una de las mayores dificultades que presentan los estudiantes en Educación Parvularia es iniciar el proceso de lectura y escritura como tal, evidenciándose esto en: el silabeo al leer; la no pronunciación de algunas letras - incluso palabras - y no hacen diferenciación de una letra con otra tanto en la fonética como escritura. Ahora bien, hay un elemento que se ha integrado al currículo educativo $y$ que ha resultado un apoyo pedagógico innovador en las aulas, estas son las Tecnologías de Información y Comunicación (TIC), que permiten que el proceso de enseñanza de la lectura y escritura sea cada vez más interactivo y motivante; además de ser un recurso tecnológico creativo que lo favorece. El docente en el aula se apoya del docente que trabaja con softwares educativos (libres o con licencia), proporcionándole de esta manera al estudiante un refuerzo de las letras que ha visto en el aula de clase. Es aquí donde las TIC ayudan a que no sea un proceso tedioso o lento, motivando a los estudiantes a superar algunas dificultades en esta área. Sin embargo, no en todas las instituciones se cuentan con estos recursos o si los poseen son limitados, pero que aun así los docentes buscan cómo incorporarlas en el proceso de lecto-escritura.

Partiendo de lo anterior, durante la investigación se indagó y recolectó información acerca del uso e integración curricular de las TIC en las aulas de Educación Parvularia en el sector privado y en las instituciones educativas públicas. Con la información recabada se dio respuesta a la pregunta de investigación ¿Cuál es la influencia de las TIC como apoyo pedagógico en el proceso de lecto- escritura de educación preescolar de las secciones de niños de 6 años de centros educativos pú- 
blicos y privados de la ciudad de Santa Ana? Además, se explicó, identificó, describió y evaluó la influencia de las TIC como apoyo pedagógico en el proceso de lecto-escritura en Educación Preescolar de las secciones de 6 años de centros educativos públicos y privados de la ciudad de Santa Ana.

Durante el desarrollo del trabajo se descubrió que las estrategias metodológicas que incorporan los docentes, utilizando las TIC en el proceso de aprestamiento para la lecto-escritura son variadas: desde proyecciones con cañón multimedia, visualización de videos o películas. De esta manera, hoy por hoy, la computadora es un recurso tecnológico que potencia, favorece y desarrolla el proceso de lecto-escritura «las TIC aplicadas al proceso de lectura aportan un carácter innovador y creativo, tienen una mayor influencia y beneficia en mayor proporción al área educativa, ya que la hace más dinámica» (Fernández, 2010, p.5).

La tecnología se ha procurado incorporar en esta área, ya que se pueden prácticamente trabajar todos los ejes temáticos de diversas formas, y a través de diferentes canales; es decir, lo visual, auditivo y kinestésico, haciendo el proceso más efectivo, especialmente, porque conlleva una mayor motivación ante los aprendizajes. En este sentido, el proceso se vuelve más dinámico. La lecto-escritura es un proceso en cual intervienen "procesos psicológicos como la percepción, la memoria, la cognición, la metacognición, la capacidad inferencial, y la conciencia» (Montealegre y
Forero, 2006, p.26). Cuando se empieza a desarrollar este proceso, se puede hacer a través de juegos e imágenes, para que hagan una lectura ideo-visual, como lo explica Pozo (2007) «que dentro del contexto global-natural, basado en las ideas y la visualización de las palabras parte de la frase y la palabra para llegar, por el análisis, a la distinción de la palabra, la sílaba y el fonema».

Asimismo, las TIC como estrategia pedagógica para fortalecer el proceso de lecto-escritura es algo que los niños, a temprana edad, tienen la oportunidad de aprender; por lo tanto, como lo plantea Marqués (2006) «la escuela deberá, propiciar la adquisición de competencias TIC para que los niños cumplan un papel más activo y, en el futuro, puedan gestionar su propia formación que se desarrollará a lo largo de la toda la vida» (p.7). En este sentido las instituciones educativas deben poner especial énfasis en la incorporación de las TIC en Preescolar. Además, las TIC constituyen como lo explican Henao y Ramírez (2008)

Un poderoso agente de cambio para el rediseño de ambientes, condiciones, métodos y materiales didácticos, varias experiencias han mostrado que una adecuada incorporación y utilización de TIC en el entorno educativo puede generar cambios con mayor énfasis en: construcción de conocimiento, ritmos de aprendizaje, cambio de métodos de lectura y escritura, mejores posibilidades de integrar la comunicación verbal y visual (p.12) 
Dicho lo anterior, al estudiante de Preescolar que inicia con este proceso le resulta innovador y enriquecedor hacer uso de la computadora para aprender a leer y escribir. Monsalve y otros (2008), citando a Aguaded (2001), afirman que «los medios audiovisuales han incorporado nuevas formas de presentación de la información, superando el modelo verbal con propuestas multisensioriales, donde la imagen aporta componentes icónicos muy intuitivos y motivadores» (p.110). Desde este punto de vista, los docentes deben aprovechar este recurso para que la lecto-escritura se realice de manera más fluida, permitiendo transformaciones en diferentes áreas educativas. Además, «ofrecen recursos audiovisuales, multimediáticos, y de redes informáticas que traen consigo nuevos conocimientos, instrumentos y procedimientos para acceder a la información de forma más dinámica, novedosa e interactiva, proporcionando a la educación recursos tecnológicos que transforman y enriquecen el aprendizaje» (Monsalve y otros, 2008, p.93).

Por lo tanto, el propósito fundamental de estas herramientas en el aula es mejorar los aprendizajes de los estudiantes, provocando en él un interés particular por aprender a leer y a escribir. En tal sentido, Valencia y otros (2007) citan a Giraldo (2002), específicamente en que «la utilización del computador como herramienta de escritura puede llegar a ser algo tan natural como el garabateo que espontáneamente hace un niño cuando se le presta un lápiz» (p.49).
En la actualidad se han creado muchas herramientas y software para fortalecer el proceso de lecto-escritura en preescolar:

Los programas más utilizados son:

- Pipo: es un método interactivo y progresivo para aprender a leer. Además, es un método flexible que permite ser adaptado a las diferentes metodologías de los docentes, y a las diferentes capacidades de los estudiantes. (Ministerio de Educación, Perú, 2004, s/n).

También dentro de la Web se encuentran páginas educativas de las cuales los docentes de informática pueden hacer uso, ya que son de gestión libre, como por ejemplo:

- Recursos para educación infantil de Marife Lara: es una selección de recursos en donde se encuentran multitud de actividades para repasar, reforzar y ampliar los contenidos del currículo. Entre ellos están "Juegos de la oca para aprender a leer"; "Captain Jack 2"; “Algaida para cinco años" y otros. (Méndez, 2009, s/n).

- JCLIC: es un soporte para actividades de lectoescritura: asociación sonido-grafía, palabra imagen, texto-imagen, y de ejercitación de la memoria visual y auditiva, que es imprescindible en ese proceso de aprendizaje. (Padilla, 2009, p. 6) y otras.

Asimismo, es importante analizar y seleccionar las herramientas para poder aplicarlas en el proceso de aprendizaje de la lecto-escritu- 
ra. Montesinos (s.f.) considera que es necesario tomar en cuenta los siguientes criterios:

- Facilidad de uso e instalación

- Versatilidad

- Calidad del entorno audiovisual

- Calidad de contenidos

- Navegación e interacción

- Capacidad de motivación

- Potencialidad de los recursos didácticos (pp. 20-21).

Al usar la tecnología en el aula puede ser de mucho beneficio para los estudiantes, Valencia y otros citando a Poole (2007) las detallan de la siguiente manera:

- El uso de materiales dinámicos, interactivos o multimediales impacta a todos los estudiantes, captando su atención y despertando confianza en ellos.

- La constante interacción y participación de los estudiantes con las herramientas tecnológicas, estimula la iniciativa frente a la toma de decisiones por las rápidas respuestas que le exige el computador a sus acciones. (p.40)

Es por ello que la integración curricular de las TIC en los procesos de lecto-escritura es un gran beneficio para los estudiantes. Moreno (citando a Sánchez 2001) señala que «usar curricularmente las TIC puede implicar utilizarlas para los más diversos fines con el propósito claro de apoyar un aprender de un contenido, un concepto, un proceso, una disciplina curricular específica» (p.39). De igual manera, para que exista una real integración curricular de las TIC se debe:

- Usar las TIC para planificar estrategias que faciliten la construcción del aprender

- Usar TIC en el aula

- Usar las tecnologías para apoyar las clases

- Usar tecnologías como parte del currículo

- Usar las tecnologías para aprender el contenido de una disciplina

- Usar software educativo de una disciplina

- Uso de computador con software de juegos educativos, internet, fotos, videos juegos para dibujar en Paint y otros (Moreno, 2009, p.40).

Por otro lado, las formas más comunes de organizar el uso de TIC se realizan en «el laboratorio de computación y la sala de clases donde los docentes suelen apoyar su trabajo con el uso de estas» (Abarzúa y Cerda, 2011, p. 18). Es importante trabajar con los estudiantes - principalmente en la edad temprana - la competencia digital; la cual se refieren a las «habilidades para buscar, obtener, procesar y comunicar información, para transformarla en conocimiento, incorporar diferentes habilidades, como elemento esencial para informarse, aprender y comunicarse» (Rodríguez, 2013 , p. 7). En este caso, familiarizarse con las letras y la escritura de una manera lúdica. 


\section{Metodología}

La investigación fue abordada desde un planteamiento explicativo-descriptivo, teniendo como propósito explicar las condiciones del uso de las TIC como apoyo en el proceso de lecto-escritura de Educación Preescolar; así como describir las actividades desarrolladas en las instituciones estudiadas, con respecto a la aplicación de las mismas en el aula de clase y de informática.

La muestra para el estudio fue intencionada, porque previamente se hizo una exploración de la población a estudiar, y luego se seleccionaron las instituciones que cumplían con los requisitos para la investigación; es decir, el procedimiento consistió en seleccionar centros educativos públicos y privados de la ciudad de Santa Ana, en cuya estructura existiera el nivel de Educación Preescolar; pero además se hiciera uso el centro de informática. Debido a ello, la muestra estuvo conformada por un centro educativo público - con la sección de preparatoria anexa -; un kinder público y siete colegios privados.

Asimismo, se abordó a nueve docentes encargados de la sección de seis años y a ocho docentes de encargados de impartir la clase de informática. Las técnicas e instrumentos para la recolección de datos fueron: la entrevista en profundidad, con su respectiva guía de entrevista; y la observación directa, utilizando una lista de cotejo en el desarrollo de la clase de informática. Po supuesto, para la ejecución del estudio se contó con la previa autorización de los directores para ingresar a la institución, y así poder recolectar los datos necesarios.
En lo referente al análisis de la información, la misma fue sometida a un estudio sistemático y deductivo que permitió interpretar los datos en función de los objetivos planteados.

\section{Resultados}

\section{Estrategias metodológicas que incorporan los docentes utilizando las TIC en el proce- so de aprestamiento para la lecto-escritura}

A través de la entrevista se encontró que las docentes encargadas de las aulas aún utilizan la enseñanza tradicional. Se evidenció que ellas siguen empleando el método silábico; es decir, enseñan las vocales, silabas simples y compuestas para luego ir formando palabras hasta finalmente constituir frases. Al mismo tiempo aplican el eclecticismo, es decir, una mezcla de todos los métodos para la enseñanza de la lectura y escritura.

Fue relevante que una de las entrevistadas mencionara la utilización de uno de los métodos sintéticos, específicamente el llamado "fonético". Este modelo consiste en realizar sonidos onomatopéyicos; de manera que los niños asocien los sonidos con las letras. De esta forma, los estudiantes aprenden a través de cantos, poemas y cuentos.

El total de entrevistadas hicieron énfasis en la necesidad de trabajar la motricidad gruesa y fina en los niños primero; ya que esta les permite a los estudiantes conocer conceptos como arriba, abajo, derecha, izquierda, para luego trasladar estos movimientos hacia los trazos de las letras en el cuaderno. Con res- 
pecto a las técnicas que utilizan con esta finalidad se encuentran: el bruñido, rasgado, recortado y pegado; no obstante, otra docente utiliza la arena para que los niños hagan trazos.

Por su parte, otra profesora hace uso de los ficheros de lectura. En esa modalidad, durante la semana, los alumnos trabajan la letra mediante la realización de trazos en la mesa, en el aire, las moldean con plastilina, sobre el pasto y apresto en el cuaderno. Otra de las formas para la enseñanza de la lecto-escritura es transcribir, ya que según una de las docentes, esta actividad estimula la coordinación ojo mano en los niños, reforzando las palabras y la ortografía.

En una de las instituciones que formaron parte del estudio, una docente utilizaba el método VAKT (visual, auditivo, táctil y kinestésico). Bajo este método, ella primero trabaja con los alumnos a su cargo una historia sobre la letra, la cual obtiene de un programa llamado "Letrilandia", que contiene canciones para que los niños las escuchen. Luego, ellos empiezan el trabajo en el cuaderno, escribiendo las palabras que hayan identificado; después escriben frases, y por último, redactan un texto. Esta es la forma particular en que la institución ha establecido - no solo el orden lógico -, sino también la enseñanza del proceso de lectura y escritura dentro de ella.

$\mathrm{Al}$ referirse a libros de apoyo para trabajar la lecto-escritura de forma tradicional, una de las docentes mencionó la utilización del libro "Bernardito" y otra, un libro del Editorial Santillana, los cuales son tomados como base para hacer fichas de lectura e incorporarlas en la lecto-escritura. La docente que usa el libro de Editorial Santillana explicó que, dentro de la semana, hay un día específico en que esta ficha se expone en la pizarra digital interactiva (ver figura 1), para que una vez los niños ya han hecho el trazo, escuchado el sonido y relacionado la letra con objetos, se les coloca un video de acuerdo a la letra, antes de que ellos se vayan a casa. En cuanto a otras dos instituciones, estas utilizan una plataforma llamada TBOX; en ella suben información para que los padres de familia descarguen los archivos y repasen en casa lo estudiado por sus hijos en el colegio, durante la jornada matutina. Esta actividad es corroborada por las docentes al día siguiente porque, previo a la clase, hacen una retroalimentación del tema visto anteriormente.

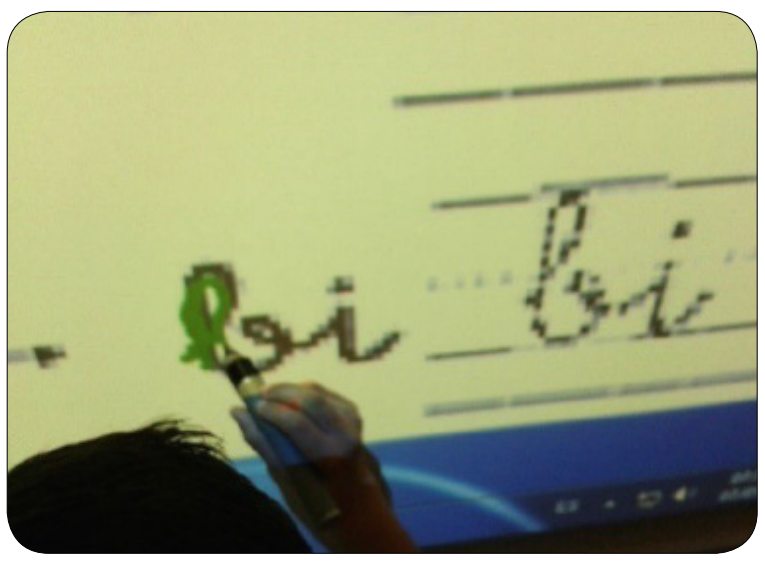

Figura 1. Fotografía tomada en el momento que un estudiante hace uso de la pizarra digital.

Al referirse a las TIC como una estrategia que apoya al proceso de escritura, una de las docentes consideró que no es muy factible utilizarla, porque los trazos de las letras no son iguales; por ejemplo, en el programa de 
Microsoft, Paint, el trazo es distorsionado, a diferencia de cuando los estudiantes practican las letras en la pizarra o en cartel. Aunque, la misma docente mencionó que utiliza la tecnología en el aula, cuando muestra los videos en el salón de clases y aparecen letras o palabras que ya han estudiado los estudiantes, ellos inmediatamente las reconocen, las mencionan y las escriben.

Tres docentes expresaron que no utilizan la tecnología en el aula porque tienen otras materias que desarrollar y no tienen los recursos para implementarlos en el aula de clase; pero que se apoyan en los docentes de informática, para solicitarles que les coloquen algún programa o juego para reforzar las letras estudiadas en el salón de clases. Esto ha permitido observar a los docentes que los niños desarrollan otras destrezas, por ejemplo, identifican con rapidez las letras y relacionan sonidos onomatopéyicos con estas.

Al referirse al tiempo que tienen las profesoras de aplicar metodologías tradicionales, este varía, ya que van desde los dos años hasta los cuatro meses. Las que tienen menos tiempo comentan que su demora se debe a la implementación de las nuevas metodologías para la enseñanza de la lecto-escritura dentro de la institución.

Se conversó con los docentes encargados de impartir informática a los estudiantes de 6 años, para conocer su opinión respecto a las TIC en el proceso de lecto-escritura, obteniendo las siguientes valoraciones:
Los docentes de informática manifestaron que al inicio del año escolar no es conveniente iniciar con software enfocados en la lecto-escritura, sino que primero se desarrollan otras destrezas como por ejemplo: uso del ratón, identificación del teclado, conceptos de tamaño y forma, así como herramientas básicas de los programas que utilizarán en su momento dentro de la clase. Pero es a mediados del año escolar en donde empiezan a presentárseles actividades de lecto-escritura.

Uno de los programas que los docentes mencionaron es el llamado "Pipo", en el que los alumnos pueden ir formando palabras. Hay otra actividad en la que les aparecen dibujos con una o dos letras conocidas por ellos, entonces las tienen que completar para así ir aprendiendo a leer palabras cortas; este programa es efectivo porque las actividades implican jugar y ver animaciones que los motivan a querer aprender a leer. Otro de los docentes usa el programa Paint, en este los niños pueden trabajar en el trazado de letras, escritura de su nombre y frases que ellos ya han visto en clase para que se vayan familiarizando con el proceso (ver Figura 2). El mismo docente explicó que dentro de su planificación tiene programado que los niños usen el software Wordpad para que los estudiantes escriban un poco más, colocarles frases a los dibujos o que relacionen dibujo con palabra. 


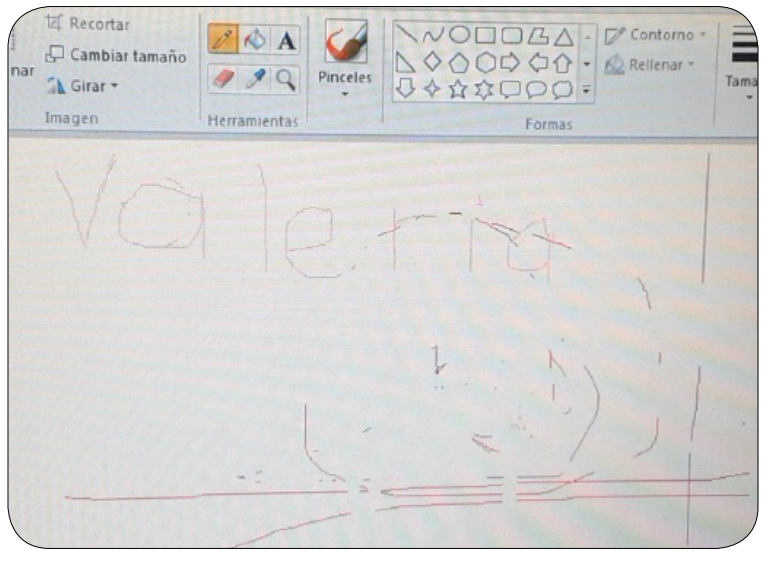

Figura 2. Fotografía tomada en la clase de computación, uso del software Paint

Dentro de las metodologías que utilizan los docentes de informática se encuentran la explicativa y práctica; sin embargo, tres docentes no hicieron ejemplos antes de impartir la clase a los estudiantes.

Dos de las instituciones que formaron parte del estudio, utilizan Tbox planet; este es un programa un poco más avanzado donde los niños tienen que entrar con una contraseña, por lo que tienen que reconocer las letras. Este sirve como un refuerzo porque hay programas que tienen figuras y pueden interpretarlos con su nombre a pesar que no pueden leer lo relacionan por medio del silabeo, la letra de inicio, la vocal o la consonante. Incluso, en la clase se pudo observar que a los estudiantes se les enseña a navegar en internet buscando cosas sencillas. Además, ellos se "logean" (es decir, inician sesión) para ingresar al Tbox; por lo tanto, deben identificar letras. Otro elemento que se usa en una de las instituciones educativas privadas es Bee bot. Este es un robot en forma de abeja, que les ayuda a seguir indicaciones y desarrollan las dimensiones con respecto al espacio y lateralidad (ver figura 3 y 4 ).

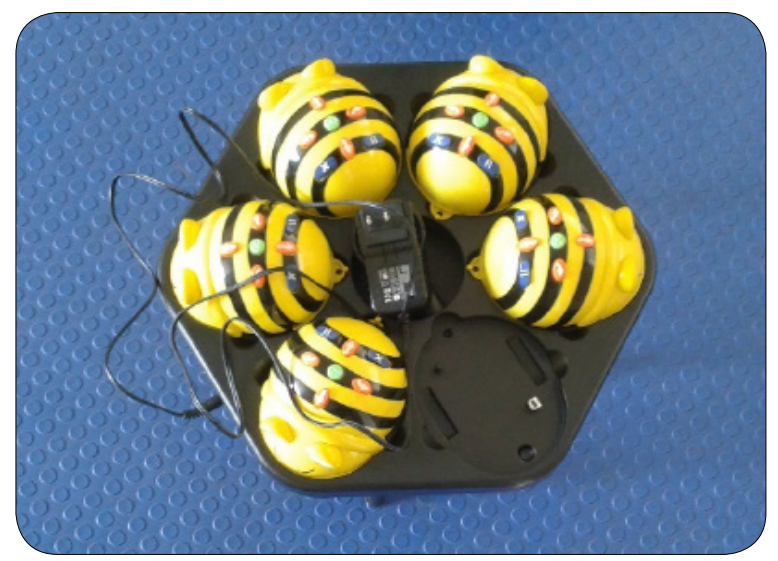

Figura 3. Fotografía tomada en clase de computación de los robots Bee bot.

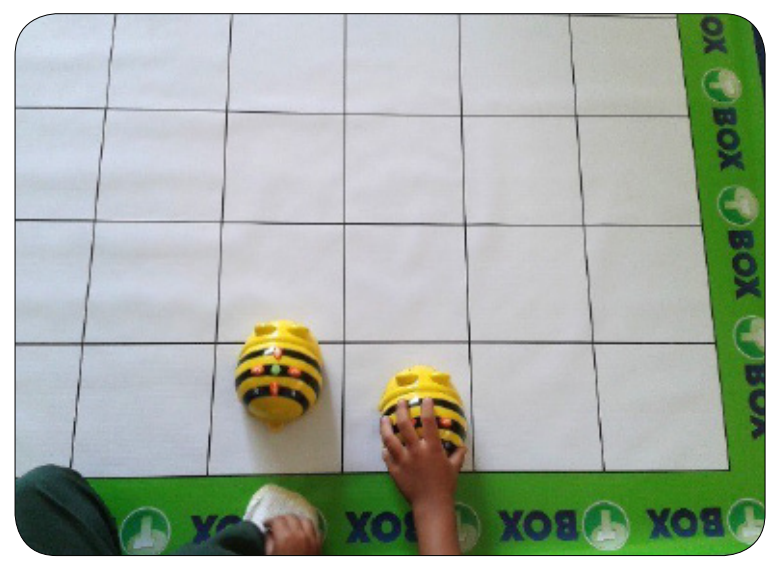

Figura 4. Fotografía tomada en institución educativa que formo parte del estudio, niños programando el robot Bee bot.

En una de las clases de computación se observó el funcionamiento del software EDUCARE. En él los niños estaban relacionando letras con las dependencias de la casa, al mismo tiempo que escuchaban palabras como: cocina, comedor, baño y otras; después ellos tenían que escribir la palabra, permitiéndoles el desarrollo de varias habilidades a nivel visual, auditivo y kinestésico. En otra institución, se observó que a los estudiantes les gustaba un programa en el que las letras caían, permi- 
tiéndoles recogerlas, haciendo clic sobre cada una ellas, y así para formar una palabra. Otro software utilizado en una institución pública es el "Conejo lector", en donde se trabaja la lateralidad botón izquierdo-derecho.

Con respecto a los Recursos TIC en el desarrollo del proceso de aprestamiento para la lecto-escritura, tres de las docentes en el aula no utilizan tecnología, porque no tienen tiempo y los recursos para implementarlas en el aula. De tal manera implementan recursos tradicionales como: juguetes legos, crayolas, colores, libretas y cuadernos. Vale la pena hacer mención que una de las docentes comentó que: «he comprobado que si el niño no tiene equilibrio, no está preparado para la lecto-escritura, por lo que para mí es necesario trabajar primero la motricidad y equilibrio en los estudiantes».

Por otra parte, dos de las docentes entrevistadas comentaron que cuando necesitan mostrar a los estudiantes una letra hacen uso del proyector multimedia; y luego pasan a cada uno de los niños para que realicen el trazo. También pueden ver imágenes de las vocales o consonantes para que relacionen letra con la figura, así como canciones y poemas. Estas actividades las realizan en el salón destinado para audiovisuales.

Una docente utiliza como recurso una grabadora para reproducirles canciones; les pide que las escuchen e identifiquen palabras que posean las letras con las que están trabajando. Otra de ellas, utiliza la televisión en el aula, proyectándoles películas a los niños para que identifiquen letras y palabras que han estudiado durante la semana, y luego les refuerza haciéndoles un dictado.

Las docentes opinan que utilizar las TIC en el salón de clases es una ventaja porque los niños están más atentos a lo que se desarrolla; por ejemplo, cuando se les proyecta algún video. $\mathrm{Al}$ incorporar este insumo dentro del proceso se refuerzan los temas que se están desarrollando.

Según lo expresado por las profesoras, no encuentran desventajas al incorporar las TIC; lo que sucede es que a veces no se cuenta con los recursos necesarios para implementarlos propiamente en el aula y tienen que recurrir a lo tradicional. Una docente comentó que una desventaja que ella observa en las alumnas que llegan por primera vez a la escuela, y son asignadas a su salón, prácticamente desconocen sobre el tema de las TIC; haciendo que el proceso de lecto-escritura sea lento porque se parte de cero, y es necesario encaminarlas en la utilización de las herramientas. Además, hay que agregar que en el sistema público solo se realiza una noción de reconocimiento de letras, pero no se les enseña a leer directamente a los estudiantes a nivel de Preescolar, ya que esta actividad está reservada para cuando ellos ingresen a primer grado.

En las instituciones que formaron parte del estudio se encontró que los recursos con los que principalmente cuentan los docentes de informática son las computadoras; específicamente, en cuatro instituciones se tiene un proyector multimedia. Los softwares que se 
utilizan para desarrollar la clase son: Pipo, Educare, Jump Star, TBox, Disney, Paint, Word Pad, Linux y Gcompris. Una docente que imparte informática recomendó el software educativo Zebra, el cual ayuda al conocimiento de las letras; además posee un refuerzo, mediante la utilización del mouse, en donde se deben identificar letras y palabras.

Con respecto a otras actividades educativas con uso de tecnología, una de las docentes expresó que le encantaría implementar la robótica dentro del proceso de lecto-escritura, porque existe un software asociado que ayudan a los niños a desarrollar la lógica, comprensión y razonamiento, en vista que a ellos a veces les cuesta seguir indicaciones; pero la robótica le ayuda en ese aspecto. El único problema es lo económico, ya que el costo del equipo es de $\$ 600.00$ dólares por cada estudiante.

Con respecto al funcionamiento de las computadoras, de las nueve instituciones que formaron parte de la investigación: en cinco de ellas, todas las computadoras están en perfecto estado; mientras que en las restantes existen una o cinco computadoras que no funcionan, por lo que los estudiantes deben compartir equipo. Ese detalle se pudo verificar en la observación de la clase. Pese a ese inconveniente, los estudiantes trabajan bien; reflejándose un fomento del trabajo en equipo. No obstante, existe otro pormenor: no en todas las computadoras se pueden conectar los audífonos.
En otra institución solo se cuenta con siete computadoras, haciendo que la docente organice un día para cada sección, dividiéndolas en grupos de siete niños por clase. En otro caso, solo se cuenta con cuatro computadoras, pero como los grupos de niños son pequeños, en cada equipo se ubican de dos a tres niños para recibir la clase.

Todos los docentes que imparten la clase de informática no ven desventajas en el uso de las TIC; simplemente recomiendan tener un cuidado especial con lo que los niños ven en internet, ya que la habilidad que ellos poseen para manejar la computadora es bastante desarrollada.

Asimismo, consideran que las TIC son herramientas con las que se logra mucho; pero el problema son la orientación inadecuada que se les brinda a los niños, desaprovechándose el potencial de los softwares educativos.

\section{Integración curricular de las TIC en el pro- ceso de aprestamiento para la lecto-escritura}

Todas las docente entrevistadas coinciden que han podido integrar las TIC ya sea en el salón de clases o exclusivamente en el centro de cómputo, logrando desarrollar en los estudiantes habilidades lingüísticas (fonológica, léxica, sintáctica, semántica) y un aprendizaje significativo. Además, mencionaron que con los juegos los educandos aprenden más rápido y se mantienen motivados durante la clase.

La opinión de las docentes respecto a los programas educativos concuerda que estos solo 
proponen que los estudiantes escuchen cuentos y canciones; cubriendo solo el área de lo auditivo, pero no hay mucha relación de la tecnología con el proceso de lecto-escritura. Sin embargo, viendo la situación desde otra perspectiva, las TIC flexibilizan el proceso cuando se cuentan con los recursos, ya que se pueden diseñar las técnicas, métodos y estrategias que ellos proponen, pero acomodándolas a la realidad en la que viven día a día los estudiantes; siendo el momento idóneo cuando los estudiantes asisten al centro de cómputo, porque se refuerza lo que se trabaja en el aula.

Al referirse a las actitudes de los niños con respecto a la clase de computación la opinión de los docentes es que se les observa con mucho entusiasmo, independencia y una mayor responsabilidad en el uso de las máquinas.

\section{Discusión}

Las estrategias metodológicas que los docentes utilizan, principalmente en el aula de clase, son las tradicionales; por ejemplo, transcripción del libro al cuaderno o de la pizarra al cuaderno; lectura guiada, dictados y las respectivas planas, haciendo reflexionar en que estas técnicas siempre son necesarias en el proceso de enseñanza aprendizaje de la lectoescritura, porque estas sirven de refuerzo dentro del proceso, por lo que no hay que dejarlas a un lado. De estas formas las TIC se convierten en un complemento para mejorarlo.

Con respecto a los recursos tecnológicos que se implementan en el salón de clase, ellos son mínimos porque no en todas las instituciones cuentan con el suficiente recurso económico para comprar equipo e instalarlo. En los centros de cómputo se trabaja de la mejor manera posible con las computadoras que se poseen. Esto demuestra que "querer, es poder", ya que en algunas instituciones solo se cuenta con siete o cuatro ordenadores y las docentes de informática se han organizado para poder impartirles las clases a los estudiantes.

En una institución educativa privada se ha incorporado la Pizarra Digital Interactiva, innovando la forma de enseñar a leer y a escribir a los estudiantes; procurando tener estos recursos a la mano, y utilizarlos con el objetivo de mejorar este proceso. Pero, cabe señalar que se debe tener un equilibrio entre los métodos tradicionales y el uso de las TIC en el aula para que la metodología sea variada en la enseñanza de la lecto-escritura.

Desde el punto de vista de los docentes, la integración de las TIC al currículo educativo de Parvularia se está realizando en pequeños pasos, porque la realidad en las aulas del país no lo permite en su totalidad por varios factores uno de ellos es el factor económico, ya que el Ministerio de Educación no logra dar abasto a todas las instituciones educativas públicas con lo que se refiere a equipo informático; por el contrario, en las instituciones educativas privadas se cuenta con estas facilidades para los estudiantes.

El aprendizaje de ciertas técnicas, el uso de procesadores de texto, los procedimientos de búsqueda en Internet, nociones en el caso de 
la Parvularia, y reconocimiento de letras en el teclado; entre otras, deben orientarse de manera secuenciada, específicamente en el área de lecto-escritura. Las estrategias que implican el uso de las TIC requieren un marco de actuación que debe ser objeto de los correspondientes acuerdos en los centros escolares tanto públicos como privados.

Los docentes deben ser autodidactas para poder mejorar su práctica pedagógica, hacer una búsqueda en internet o compartir con otros colegas métodos y técnicas que ayuden a mejorar el proceso de lecto-escritura incorporando las TIC. Asimismo, deben tomar en cuenta que las actividades en las que se haga uso de estas, siempre deben concebirse, programarse y rea- lizarse teniendo en cuenta su relación con los objetivos, contenidos y criterios de evaluación formulados en el currículo y en el proyecto educativo del centro educativo.

Finalmente, se debe considerar que las TIC ayudan a desarrollar habilidades de lectura y escritura, haciendo el proceso más interactivo y flexibilizando el currículo. Es de aprovechar que a los estudiantes les encanta el momento de ir al centro de cómputo para reforzar los contenidos que se han desarrollado en el salón de clase; asegurando un aprendizaje eficiente en lo que se ha explicado con anterioridad, ya que no hay nada más gratificante para un docente que ver en el rostro de sus estudiantes la expresión de felicidad cuando dicen: "Ya sé leer y escribir".

\section{Referencias}

Abarzúa, A y Cerda, C. (2011). Integración curricular de TICen educación parvularia. Revista dePedagogía, Vol. 32. N 90. Recuperado de http://www.academia.edu/1588548/Integraci\%C3\%B3n_ Curricular_de_TIC_en_Educaci\%C3\%B3n_Parvularia

Fernández, F. I. (2010). Las TIC en el ámbito educativo. Revista Eduinnova. Vol. 15. Recuperado de www.eduinnova.es/abril2010/tic_educativo.pdf

Henao, A. O y Ramírez S. D. A. (2008). Propuesta didáctica para la enseñanza de la lectura y escritura con un enfoque socio-constructivista y apoyada en Tecnologías de información y comunicación. Recuperado de http://www.academia.edu/734830/propuesta_did\%c3\%81ctica_para_la_ enselanza_de_la_lecturay_la_escritura_con_un_enfoque_so-cioconstructivista_y_apoyada_en

Marqués, G. P. (2006). El papel de las TIC en el proceso de lecto-escritura. Revista Planeta Grandes Publicaciones. Education. Recuperado de http://www.librodenuestraescuela.com/Data/Pdf/ Revista\%20TicOk-cast-.pdf

Méndez, D. (2009). Recursos para educación infantil. Recuperado de http://www.educacontic.es/ blog/recursos-tic-para-educacion-infantil

Perú, Ministerio de Educación. (2004). Las TIC como recurso en el acceso a la lecto-escritura. 
Área de Gestión Pedagógica, Centro de Investigación TIC. Recuperado de http://portal.perueduca.edu.pe/boletin/0_link/b_41/lecto.pdf

Monsalve, M.E y otros (2008). Diseño y experimentación de una estrategia didáctica en el área de lenguaje apoyada en TIC, para cualificar los procesos de enseñanza y aprendizaje en la escuela nueva. (Tesis de licenciatura). Universidad de Antioquía. Facultad de Educación. Medellín, Colombia. Recuperado de http://didactica.udea.edu.co/descargables/escuela_nueva/fscommand/ informefinal.pdf

Montealegre. R y Forero. L. (2006). Desarrollo de la lectoescritura: Adquisición y dominio. Red de Revistas Científicas de América Latina, el Caribe, España y Portugal. Acta Colombiana de Psicología, vol. 9, núm. 1. pp. 25-40. Recuperado de http://www.redayc.org.org/articulo.oa?id=79890103

Montesinos, M. D (s.f) Las TIC como recurso en el acceso a la lecto-escritura. Curso telemático: Acceso a la Lecto-escritura. Recuperado de http://servicios.educarm.es/templates/portal/ficheros/websDinamicas/97/t06.pdf

Moreno, C. V. (2009). Integración Curricular de Tecnologías de la Información y la Comunicación en el nivel de Educación Parvularia. (Tesis de maestría). Universidad de Chile. Universidad de Chile Facultad de Ciencias Sociales. Santiago, Chile. Recuperado de http://www.tesis.uchile.cl/ tesis/uchile/2009/cs-moreno_v/pdfAmont/cs-moreno_v.pdf

Padilla, C. R. (2009) La escritura en la educación primaria. Revista digital Innovación y Experiencias Educativas. No 15 . Recuperado de http://www.csi-csif.es/andalucia/modules/mod_ense/ revista/pdf/Numero_15/RAFAEL_PADILLA_2.pdf

Pozo, A. M. (2007). Desde L'Ermitage a la Escuela rural Española: introducción, difusión y apropiación de los centros de interés decrolyanos (1907-1936). Revista de Educación. No Ext. Recuperado de http://www.revistaeducacion.mepsyd.es/re2007/re2007_07.pdf

Rodríguez, M. (2013). Reflexión sobre las competencias básicas y su relación con el currículo. Catálogo de publicaciones oficiales del Ministerio de Educación, Cultura y Deporte. Recuperado de http://www.edu.xunta.es/web/sites/web/files/libro_competencias_basicas.pdf

Sánchez, de M. C. (2009). La importancia de la lecto-escritura en educación infantil. Revista Innovación y Experiencias educativas. $\mathrm{N}^{\circ} 14 \mathrm{pp} .1-10$. Recuperado de http://www.csicsif.es/andalucia/modules/mod_ense/revista/pdf/Numero_14/CARMEN_SANCHEZ_1.pdf

Valencia, O.C; Corrales y R. L; Betancur Q.N. (2007) Un modelo de incorporación de TICs para el área de lecto-escritura centrado en el uso de un computador y un video proyector en el aula. (Tesis de maestría) Universidad de Antioquía. Grupo de Investigación didáctica y nuevas tecnologías. Medellín, Colombia Recuperado de http://didactica.udea.edu.co/proyectogrado3/informe_final_ un_modelo_de_incorporacion_de_TICs_al_aula_de_.pdf 